NASZA DERMATOLOGIA Online OUR DERMATOLOGY Online

Source of Support: Nil

Competing Interests: None

\section{EPIDERMOTROPIC PAGETOID SPREAD AND SQUAMOUS CELL CARCINOMA IN SITU IN THE OVERLYING EPIDERMIS OF MERKEL CELL CARCINOMA}

\author{
Toshiyuki Yamamoto \\ Department of Dermatology, Fukushima Medical University, Fukushima 960-1295, \\ Japan
}

Corresponding author: Prof. Toshiyuki Yamamoto

toyamade@fmu.ac.jp
Sir,

A 71-year-old female visited the Department of Dermatology at Tokyo Metropolitan Bokuto Hospital, complaining of a nodule in the face. She was diagnosed as Merkel cell carcinoma by a skin biopsy in another clinic, and referred to our hospital for operation. A physical examination revealed a dome-shaped reddish nodule, sized $1-\mathrm{cm}$ in diameter, in the center of the left cheek. Cervical lymph nodes were not palpable. The nodule was totally removed with a margin. Histological examination revealed the tumor nests extending from the dermoepidermal junction into the deep dermis. The tumor cells had uniform small round or spindle-shape cells with hyperchromatic nuclei and numerous mitoses, which were consistent with Merkel cell carcinoma (Fig. 1, 2). Tumor cells were immunoreactive for neuron-specific enolase (NSE). Also, tumor nests were scattered within the overlying epidermis (Fig. 3). In addition, bowenoid changes were recognized within the overlying epidermis or at the border of MCC, showing many atypical disarrayed cells and clusters of large hyperchromatic nuclei (Fig. 4).

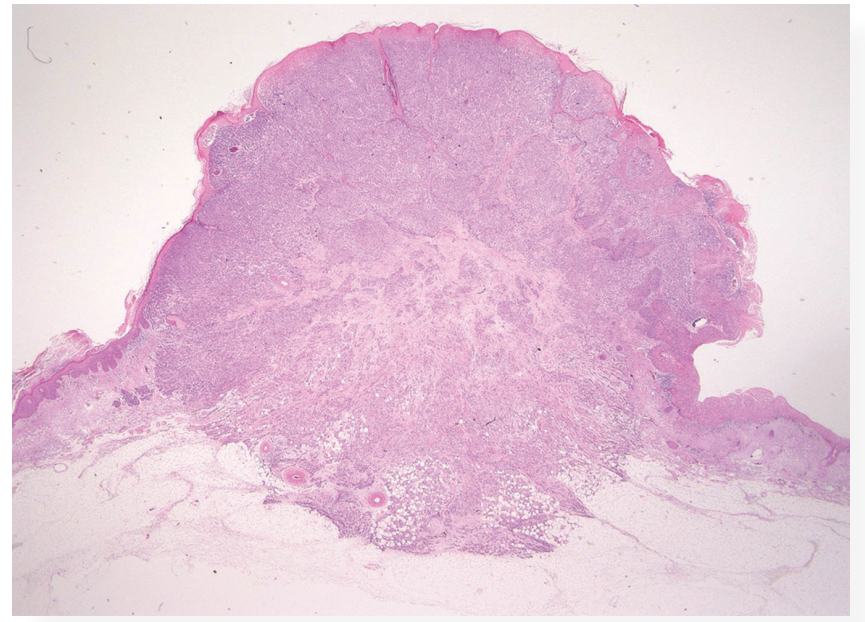

Figure 1. Overview of the histological features.

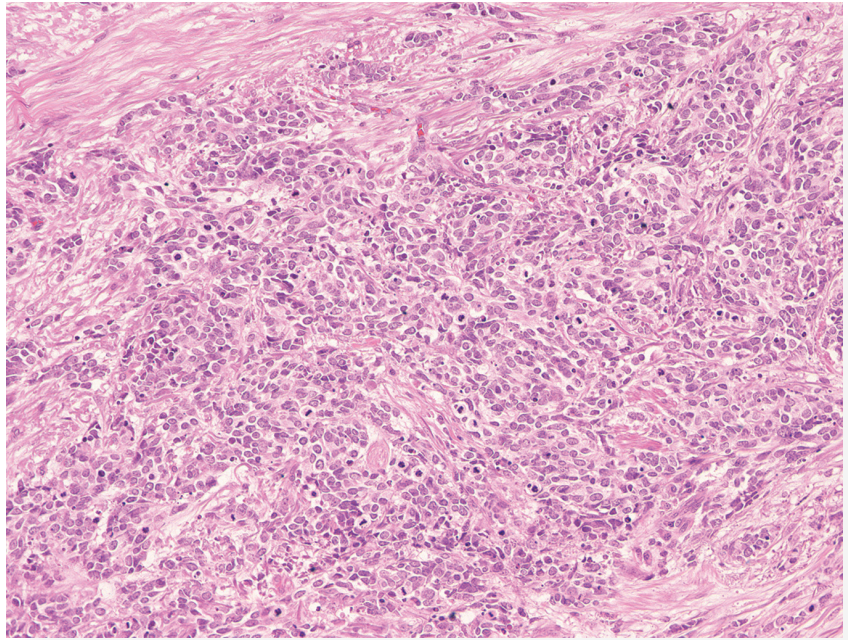

Figure 2. Higher magnification of the tumor nests showing nuclear molding, scant cytoplasm and a high mitotic rate. 


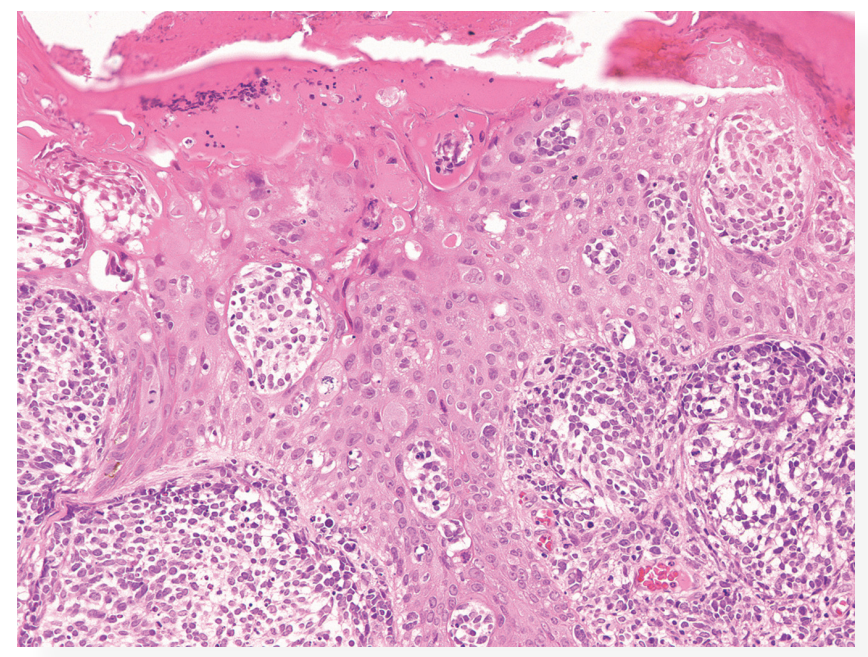

Figure 3. Pagetoid spread of MCC tumor cells in the overlying epidermis, as well as proliferation of MCC tumor nests beneath the epidermis.

Our case was a typical Merkel cell carcinoma (MCC). The most interesting feature in this case is the presence of Merkel tumor cell nests in the overlying epidermis. Epidermal involvement is occasionally seen in MCC including ulceration; however, true epidermal involvement exhibiting pagetoid or Pautrier-like pattern is relatively rare. An epidermotropic growth pattern is an uncommon feature in malignant skin neoplasms, and several cases of MCC which showed pagetoid spread in the overlying epidermis have been reported until now [1]. The mechanism of epidermotropism in MCC still remains unknown; however, affinity of tumor cells with keratinocytes is speculated, possibly via adhesion molecules. Pagetoid MCC cells show enhanced expression of epithelial membrane antigen (EMA) as compared with those located in the dermis [2], which may play a role by interfering with adhesion of the neoplastic cells with epithelial cadherin. Alternatively, epidermotropism in MCC may be related to transepidermal elimination. In our case, tumor cells were predominantly located in the dermis, extending into the deep dermis and subcutaneous tissues. Also, MCC was proliferated just beneath the epidermis without grenz zone, which may be related to epidermal invasion.

The origin of MCC has not been clarified, and proposed origins include Merkel cells, pluripotent stem cells within epidermis or adnexal epithelium, and dermal neuroendocrine cells. Previous cases in which most tumor cells exist in the epidermis suggest that MCC may arise from intraepidermal Merkel cells [3]. Further, a case of intraepidermal MCC with no dermal involvement was also reported [4]. Although examination of cytokeratin expression was not performed in our case, different staining pattern was reported between invasive MCC tumors cells and in situ zone [2,5].

Another interesting finding in the presented case is the association with Bowen's disease. MCC is often associated with squamous

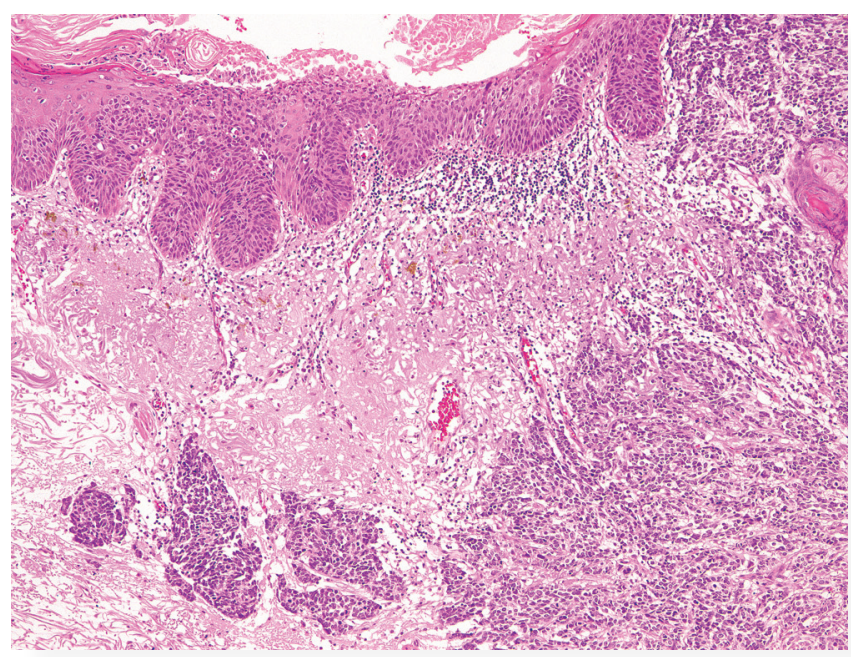

Figure 4. Bowenoid features within the overlying epidermis of MCC in the dermis.

differentiation, and overlying epidermis showing SCC in situ and invasive SCC have been reported in approximately more or less $10 \%$. Cases of MCC showing both pagetoid epidermal involvement and bowenoid changes were rare [6,7]. A similar case was recently reported in an organ-transplant recipient [7]. Although our case was not immunosuppressed, intraepidermal MCC tumor nests were intermingled with bowenoid changes in the overlying epidermis, and the bowenoid changes were also found in the border epidermis. These epidermal involvements in MCC may suggest a relationship to the epidermal or appendageal epithelia or their stem cells.

\section{REFERENCES}

1. LeBoit PE, Crutcher WA, Shapiro PE. Pagetoid intraepidermal spread in Merkel cell (primary neuroendocrine) carcinoma of the skin. Am J Surg Pathol. 1992;16:584-92.

2. Traest K, Vos RD, van den Oord JJ. Pagetoid Merkel cell carcinoma: speculations on its origin and the mechanism of epidermal spread. J Cutan Pathol. 1999;26:362-5.

3. Hashimoto K, Lee MW, D'Annunzio DR, Balle MR, Narisawa Y. Pagetoid Merkel cell carcinoma: epidermal origin of the tumor. J Cutan Pathol. 1998;25:572-9.

4. Holly B, Doug S, Tom Woo. Intraepidermal Merkel cell carcinoma with no dermal involvement. Am J Dermatopathol. 2000;22:65-9.

5. Beer TW. Merkel cell carcinomas with CK20 negative and CK7 positive immunostaining. J Cutan Pathol. 2009;36:385-6.

6. Smith KJ, Skelton HG, Holland TT, Morgan AM, Lupton GP. Neuroendocrine (Merkel cell) carcinoma with an intraepidermal component. Am J Dermatopathol. 1993;15:528-33.

7. Kanitakis J, Euvrard S, Chouvet B, Butnaru A, Claudy A. Merkel cell carcinoma in organ-transplant recipients: report of two cases with unusual histological features and literature review. J Cutan Pathol. 2006;33:686-94.

Copyright by Toshiyuki Yamamoto. This is an open access article distributed under the terms of the Creative Commons Attribution License, which permits unrestricted use, distribution, and reproduction in any medium, provided the original author and source are credited. 